http://dx.doi.org/10.4314/gjl.v6i2.2

\title{
VERBAL EXTENSIONS: VALENCY DECREASING EXTENSIONS IN THE BASÀ LANGUAGE
}

\author{
Philip Manda Imoh, David Abraham Areo, Philip Daniel Moles and Isa Gambo
}

\begin{abstract}
This work investigates verbal extensions that affect the valency of verbs in the Basà language (Western Kainji). It focuses on verbal inflections that result in the reduction of the verb's valency by one argument with regard to the basic structure. This current study attempts to investigate the morphosyntactic effects of reciprocal and reflexive affixes in the Basà sentences. The significance of this work hinges on the fact that no known work has described these processes in Basà. The language is endangered because its native speakers neglect speaking it in favour of English and Hausa. Furthermore, there is dearth of information on Basà, especially in areas of morphology and syntax, which are basic to the study of language. This study will therefore attempt to fill this existing gap in the literature. In addition to the native intuitions of one of the researchers, as a native speaker of the Basà language, data collected for this work include discourse observation, staged and elicited spoken data from fluent native speakers. It was found in the study that affixes attached to the verb root result in deriving an intransitive verb from a transitive one, and a transitive verb from a bi- or ditransitive. Both operations are triggered by verbal extensions and move the internal argument (object) to the subject position. The derived structure, therefore, is headed by a complex noun phrase but the verb no longer subcategorizes an internal argument. The work explores the morphosyntax of Basà verbs and serves as a springboard for this aspect of Basà morphosyntax. It also contributes to the morphosyntactic literature.
\end{abstract}

Keywords: Basà language, reciprocal, reflexive, valency decreasing verbal extension. 


\subsection{Introduction}

Basà language is a native language spoken by the Basà people in Kogi, Nasarawa, Benue, Niger states and all the Federal Capital Territory (FCT) councils of Nigeria. Crozier and Blench (1992) and Blench and Williamson (1988) classify Basà under Western Kainji.

This paper attempts to describe and analyze one of the resultant effects of verbal extensions in Basà, with a special focus on 'reflexives' and 'reciprocals'. No known work has described these processes in Basà. Imoh (2015) attempts a description of verbal extensions. This work is related to his work, but his focus is on causativization and applicativization. The problem this work attempts to solve is to examine whether verbal extensions also result in decreasing the valency of a verb as opposed to Imoh (2016) which studies similar morphological processes, but resulting in an opposite syntactic consequence i.e. valency increase. This will be examined by attaching affixes to verb stems and examining their effects in the sentence as a result of such extensions. The former focuses on verbal extensions that increase the valency of the verb; whereas, the present study focuses on processes that decrease or reduce the verb's valency. The investigation attempts to answer the question "What is the effect of a verb's valency when reflexive or reciprocal operator affixes attach to them?"

In addition to the native intuitions of one of the researchers, as a native speaker of the Basà language, data collected for this work include discourse observation, staged and elicited spoken data from fluent native speakers.

Technically, the term valence describes a situation of an atom's bond-forming capacity with its outer shell electrons (Brady, 1982: 109). Tesniere (1959) was the linguist who adopted this in linguistics. He refers to the bond formed by syntactic elements, which may be formed with each other or another constituent. The verb is the fundamental element of the sentence that determines valency, that is, by the transitivity or intransitivity of the verb. The concept 'transitive' refers to whether or not a verb requires an object to fill the $\mathrm{NP}$ slot in the predicate as its direct object. Any verb that requires a direct object to complete a sentence is a transitive verb; whereas, a verb that requires a direct object as well as an indirect object is bi- or ditransitive, that is, it is doubly transitive. On the other hand, any verb that does not require a direct object is referred to as an intransitive verb.

Whaley (1997: 199) argues that the valency of a verb is not fixed, "a verb in its basic form will manifest what can be referred to as its core valency", that it can be "manipulated and the morphosyntax of the language can typically increase or decrease 
valency or realign the grammatical relations of the verb's argument". This research is targeted at investigating the decrease in the number of argument(s) as a result of reflexivization and reciprocity in Basà language.

There are various ways valence may be altered. Languages have different strategies to do this. Some may be lexical, in such a case; this notion may be wrapped up in the lexical meaning of the verb without any overt change in its form. Mazengia (2012: 2) exemplifies this in English:

(1) a. Lemma killed a lion

b. The lion died

(2) a. Lemma broke the jar

b. The jar broke

In each of the cases in (a) above, the clauses are bivalent, whereas in (b), they are monovalent. Another way of making valence adjustment is morphological. This requires attaching an affix to the stem thereby creating a new form.

\subsection{Statement of the problem}

This section highlights the problems that are faced by this language that necessitate this investigation. First, the Basà language is endangered because its native speakers neglect speaking it and the language is neither written nor documented, gradually resulting in language endangerment, which is one of the major reasons for doing this research.

Secondly, there is a dearth of information on Basà, especially, in areas of morphology and syntax, which are basic to the study of language. This study will therefore attempt to fill an existing gap in the literature.

Furthermore, where affixes are attached to verb stems in the Basà language, different morphological and syntactic or both processes are triggered. This current study attempts to investigate the morphosyntactic effects of reciprocal and reflexive affixes in the Basà sentences.

\subsection{Significance of the study}

The justification for this work hinges on the fact that the morphosyntax of Basà language is highly under-described. Therefore, studying Basà language at this level will 
help to bridge the existing gap and to promote it. This descriptive study will add to the existing knowledge in the linguistic literature and create an awareness of how they operate in Basà language. It will make a meaningful contribution to scholarship and pave way for other language developers as well as for the learning and teaching languages. Furthermore, the study will also benefit other researchers with the greater understanding of the morphology and the syntax of Basà and unveil the interesting processes underlying the interface or the hybrid of morphology and syntax, especially, as it applies to verbal valency.

To the best of the researchers' knowledge, nothing has been done in this area of the Basà language; therefore, this work serves as the pioneering work and reference point to other investigators in the language. Finally, several works have been done on various aspects of Basà linguistics, such as syntax, morphology, semantics, etc. but the morphosyntactic literature generally, is very scanty. This work therefore seeks to address this gap and make a contribution to the linguistic literature.

\subsection{The Concept Reflexivity}

Reflexive refers to a process where, in a construction, the subject and the object relate or refer to the same entity (see Crystal 2008; Lyons, 1969). It is an operation where "the agent and the patient are co-referential and can be thought of as occupying a single syntactic function" (Haspelmath \& Sims 2012: 239). This process involves the action of the verb affecting the same person who performs the action. Mengistu (2000: 325) exemplifies the concept in Amharic verbs thus:

(3) at 't ' $v$ 'wash' and lac 'shave'

Derived with the prefix $t(\boldsymbol{\theta})$, which expresses the action that affects the body parts, he thus suggests that the preferred reading for (3) is that of the reflexive. On the basis of this, he generalizes and defines the concept as "the actions that are normally performed on a body part." This definition may be associated with some inadequacies with regards to what reflexive actually means. For example, $A$ may perform an action on $B$ which may never have any reflexive sense, for instance,

\section{(4) Bill injured Jane}

In (4), the action carried out on Jane's body was by Bill but does not have any reflexive sense; though the action was carried out on the body but by another person. The 
definition of Lyons better defines the concept 'reflexive', that is, "a reflexive construction is one which the subject and the object refer to the same person or thing" (1969: 361).

Haspelmath and Sims (2012: 239) argue that the reflexive is a valence changing operation where the agent and the patient are co-referential, therefore can be thought of as performing a single syntactic function. They exemplify this with Eastern American as shown in (5) and the rule given in (6) respectively.

$\begin{array}{llll}\text { may-ə } & \text { iva--um } & \text { e } & \text { Seda } \\ \text { mother-ART } & \text {-n. } \\ \text { wash PRS } & \text { AUX } & \text { eda- DAT-ART }\end{array}$

'Mother is washing Seda'
b. Seda-n
iva-cv-um
e.
Seda (NOM)-ART
wash-REFL-PRS AUX
(Kozinceva 1981: 239)
'Seda is washing (herself)'

Haspelmath and Sims (2012: 239) express the rule underlying this construction in (6) thus:

(6)
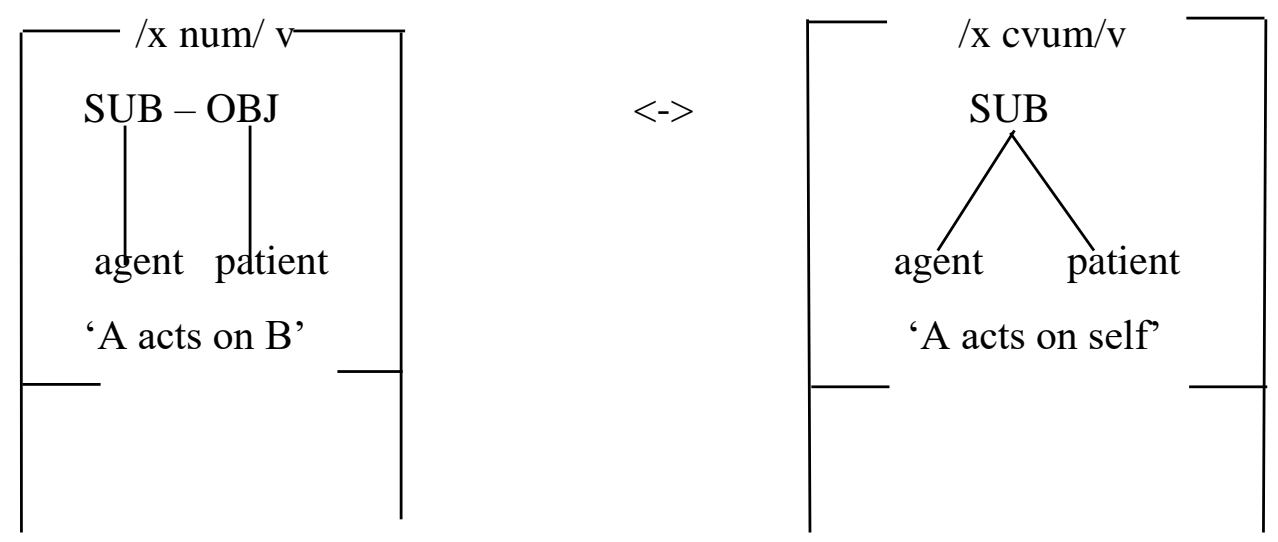

They assert that, in the reflexive voice, the meaning of the verb remains the same, but both the agent and patient are co-referential with the same index as shown in the wordschema in (6). In what follows, we shall examine another concept of valence-changing operation, which closely relates to reflexives, that is, 'reciprocal'. 


\subsection{The concept reciprocity}

In a reciprocal construction, two or more participants are involved and they act on one another. That is, semantically, in this type of construction, the two arguments of the predicate act upon each other. In such a case, the subject is equally the object, or both of them are the same. Mazegia (2012:7) opines that "reciprocals are conceptually similar to reflexives; in both cases, the agent is at the same time a patient, which in effect results in argument reduction from both semantic and syntactic viewpoints." Instead of two distinct Agent-Patient relations, which would result in four participants, the arguments would be limited to only two, i.e. Agent-Patient as well as the relation. This process consequently reduces the valency of the verb from four arguments to two in appearance (see Mazenga 2012). Mazenga (2012: 7) illustrates this in the Amharic language in (7) below:

\section{(7) Lemma-(f) nna Almazto- mərarrok ${ }^{6}-\mathrm{u}$ L- CONJ A RECP-bless REDUP-3PL.PFV 'Lemma and Almaz blessed each other.'}

He reports Leslau (1995:469) as saying; any type A or B in Amharic verb may be converted into type $\mathrm{C}$ and preceded by to- so as to express reciprocity. In order words, as shown in (7), the operator that converts any type of verb to a reciprocal is the prefix toattached to the verb stem.

Furthermore, in his comparative study of reciprocal of Amharic and Oromo languages, he reports that, the Oromo reciprocal construction is simpler. The morpheme which marks reciprocity, that is wal 'each other' directly attaches as a prefix to any conjugated transitive verb marked for plurality with no further changes to the verb stem. Example:

(8) Lemma- fi Almas wal-ejbis-an $\mathrm{L}-\mathrm{CONJ}$ A RECP-bless-3PL. PFV

'Lemma and Almaz blessed each other.'

The structure of Amharic contrasts with that of Oromo, not only by the reciprocal prefix to- but also the reduplication of the verb stem, see example (7).

Mutaka (2000:181) argues that reciprocal suffix modifies the meaning of the verb by adding the idea of reciprocity. "When suffixed to verb roots, the reciprocal suffix 
indicates that the action inherent in the verb is received by more than one element." They both function as the goal and the action of the sentence. Mutaka (2000) further contends that "inherently, transitive verbs become intransitive as the subjects of the verb (agent of the action) also function at the same time as the objects (goals/recipients of the action). Usually, the subject becomes plural as two (or more) participants in the action are at the same time agents of their own actions and goal/recipient of other's action."

The over-generalization opined by Mutaka (2000: 181) above may not account for all languages, that is, "inherently, transitive verbs become intransitive." Though the derived reciprocal predicate appears to be intransitive in some languages, it is inherently transitive. In English, for example:

\section{(9) Bill and Jane love each other.}

Example (9) shows that the verb is still transitive, because each other is a personal pronoun that refers to Bill and Jane. For languages that employ only a reciprocal affix, such an affix in such languages implies reciprocity of the action of the verb. If we try to exemplify (9) in (10) below, the sentence will be incomplete, for example:

\section{(10) *Bill and Jane love}

In (10), the sentence is incomplete because it requires an internal argument which serves as the direct object for the predicate to make a complete thought. The dark box indicates a gap.

Mutaka (2000:182-183) illustrates this concept in some African languages such as Bafut, Akoose and Tuki as shown in (11) below:

\section{a. Bafut (-nə)}

i) SùùkonəBì̀ 'Suh loves Bin'

ii) SùùbóBìkonño

Suh and Bin love+RECP

'Suh and Bin love each other.' 
b. Akoose (-عn (the $\varepsilon$ deletes in front of a vowel))

i) kòs 'to hate' kòs-n 'to hate each other'

\section{ii) Senzenéngomebékooné}

'Senze and Ngome hate each other.'

\section{c. Tuki (-na)}

\section{i) Mbárá à dingámPùtá}

Mbara he love+IMPPuta

'Mbara loves Puta.'

\section{ii) Mbárá nàPutavádíngànam}

Mbara and Puta they love+RECP+IMP

'Mbara and Puta love each other.'

In each of the three languages above, an infix operator, which attaches to the verb stem, triggers the reciprocal sense in each sentence, implying that the action characterized by the verb stem is reciprocated by the participants.

The preceding discussion has set the framework within which these verbal extensions resulting in valence reduction (reflexives and reciprocals) will be viewed in this investigation. In what follows, reflexives and reciprocals in Basà will be discussed and analyzed to examine their patterns of verbal extensions and the consequent effects.

\subsection{Reflexives in the Basà language}

The following section presents the analysis of reflexives in Basà. Each example consists of ( $a$ and $b$ ) to examine the basic structure and compare it with the morphologically inflected one to show how the reflexive affix extends the verb stem and syntactically reduce the arguments of the predicate. In each case, the valency of each predicate reduces by one argument. If, for example, a predicate is characterized by a two-place argument (i.e. a transitive verb), the attachment of a reflexive morpheme reduces it to a one-place argument 
(intransitive). If, on the other hand, a verb is ditransitive, the reflexive inflectional affix reduces it to a transitive verb where the direct object is deleted and the indirect object becomes a direct object. Consider the following examples.

a.

$\begin{array}{lll}\text { i. } \mathbf{N} & \text { swọcẹm } & \text { wotù } \\ \text { 1SG } & \text { drive-PST } & \text { car }\end{array}$

'I drove a car.'

ii. Ń màmà-swọcẹ

1SG REFL-drive-PST

'I drove myself.'

b.

i. Ń shepi Làrẹ

1SG take-PST name

'I took/drove Lare.'

ii. Gà-Làr ẹè̀mè-shepi

NOM name REFL take-PST

'Lare took/drove herself.'

c.

i. Ga Jasà na Zájẹmẹ bẹjẹ

NOM name CONJ name feed-PST name

'Jasa and Zajeme fed Zeyi.'

ii. Ga Jasa na Zájẹmẹ̀ à màmà-bẹjẹ

DET name CONJ name AGRS-REFL feed-PST

'Jasa and Zajeme fed themselves.'

d.

$\begin{array}{lll}\text { i. Bò̀ } & \text { shẹrẹ } & \text { bọ̀naà } \\ \text { 3SG } & \text { cut/slaughter-PST } & \text { cow } \\ \text { 'S/he slaughtered a cow.' } & \end{array}$




\begin{abstract}
ii. Bò̀ màmà-shẹrẹ
3SG REFL-cut/slaughter-PST

'S/he slaughter him/herself.'

e.

$\begin{array}{lll}\text { i. Gè-Jére } & \text { jibi } & \text { Swiín } \\ \text { NOM-name } & \text { beat-PST } & \text { name }\end{array}$

'Jere beat Swin.'

ii. Gè-Jére mèmè-jibi

NOM-name REFL-beat

'Jere beat himself.'

f.

$\begin{array}{lll}\text { i. Bú } & \text { lubi } & \text { Shìẹn } \\ \text { 2SG } & \text { love } & \text { name }\end{array}$

'You love Shien.'
ii. Bù mèmè-lubi
3SG REFL-love
'You love yourself.'

In each of the examples in (12), the verbs in the basic sentences are characterized by two place arguments, that is, the subject and the object. As soon as the reflexive prefix attaches to the verb stem in each example, it changes the verb from its inherent transitiveness to intransitive. Hence, in each case in (12ii), the predicate does not subcategorize an internal argument, that is, this verbal extension has the effect of decreasing the verb's valency by one argument. As such, the valency of the verb is not fixed. This morphosyntactic process manipulates the verb's valency or realigns the grammatical relations of a verb's arguments (see Mutaka 1997).

There are few verbs that, despite this process, still retain their transitivity, that is, they do not convert from transitive to intransitive; rather, they remain transitive even when the reflexive prefix applies. This set is exemplified below:
\end{abstract}


(13)

a.

i. Bì jeji bùbwa

3SG cut-PST finger

'S/he cut her/his/self.'

ii. Bù mèmè-jeji

bùbwa

3SG REFL-cut-PST finger

'S/he cut her/himself.'

b.

i. Ń dọr ẹmèni

1SG bathe-PST water

'I bathed.'
ii. Ń màmà-dọrẹ meni 1SG REFL-bathe-PST water 'I bathed myself.'

These categories of verbs are rare in Basà. Generally, when the reflexive affix attaches to the verb stem, it automatically converts a bivalent verb to a monovalent one. The following subsection analyzes reciprocals in Basà.

\subsection{Reciprocals in Basà}

Both reciprocal and reflexive processes employ the same prefix màmà-. This prefix can be modified to form different allomorphs based on the verb root to which it attaches (see examples $12 \& 13$ ). This is as a result of progressive assimilation; where the prefix, in anticipation of the phonetic properties of its host, assumes a phonetic shape with which it is compatible. They contrast simply by the reciprocal receiving an additional affix, namely, a suffix. Both of them form a single unit around the verb stem. This process is described as 'circumfixation', which is a combination of prefix and suffix treated as a single unit (Matthews, 2007: 57). This process is exemplified as follows: 
(14)

a.

i. Gà- Jére lubi Shẹ̀ṇn

NOM-name love name

'Jere loves Sheen.'

ii. Gà- Jére na Shẹ̀ẹn mòmò-lubo-nù

NOM-name CONJ name REFL-love-RECP

'Jere and Sheen love each other.'

iii. Òòmòmò-lubo-nù

3PL REFL-love-RECP

'They love each other.'

b.

i. Gà- Zájẹmẹ̀ twajẹ Rècé

NOM-name insult-PST name

'Zajeme insulted Rice.'

ii. Gà-Zájẹmẹ̀ na Rècé màmàtwaga -nọ̀

NOM-name CONJ name REFL-insult-RECP

'Zajeme and Rice insulted each other.'

c.

i. Gà-Jére imi Zèyínàba

NOM-name hate name

'Jere hates Zeinaba.'

ii. Gà- Jére na Zèyínaba mòmò-imo-nù

NOM-name CONJ name REFL-hate-RECP

'Jere and Zeinaba hate each other.'

d.
i. Ń zhegeni Hunu
1SG visit-PST name
'I visited Hunu.' 


\section{ii. Tú mòmò-zhogo-nù}

1PL REFL-visit-HAB-PST-RECP

'We visited each other.'

e.

i. Gà-Sheneni swe Zè̀kẹ mayagà

NOM-name drink-PST name wine

'Sheneni fined/punished Zeke.'

ii. Gà- Sheneni na Zệk ẹmòmò-swo-nù mayagà

NOM-Sheneni CONJ name REFL-drink-PST-RECP wine

'Shenenin and Zeke fined/ punished each other.'

$\begin{array}{lll}\text { iii. Òò } & \text { mòmò-swo -nù } & \text { mayagà } \\ \text { 3PL } & \text { REFL-drink-PST-RECP } & \text { wine }\end{array}$

'They fined each other.'

In (14), the process is characterized by valence decrease when the affix (circumfix) of reciprocity is attached to the verb stem. The semantics of the derived sentences in (ii or iii) are that, the actions which the verbs describe are mutually received or reciprocated by the same participants. The nouns also serve as the agents of the same action. The effect of this affix is a decrease in the verb's valency by one argument vis-a-vis the basic sentence. Reflexives contrast with reciprocals in the following ways:

i. In a reflexive situation, the action of the verb affects the same person(s) who performs the action, that is "the subject and the object refer to the same person or thing" (Lyons 1969:361).

ii. Reciprocity refers to a situation where two parties or participants mutually act upon each other.

The two processes are similar. In the former, the action goes to the agent or actor, but in the latter, the action is mutually carried out and the agents or participants mutually receive the action. 


\section{Conclusion}

This paper has discussed two types of verbal extensions that trigger valency decrease in Basà. The first one is a reflexive construction. In Basà, the process involves prefixing the verb stem with the morpheme màmà- which semantically implies that the action of the subject (agent) goes back to the performer of the action. This results in a decrease in the verb's valency. In such cases, a bivalent verb becomes monovalent and a ditransitive verb becomes bivalent, subcategorizing only two arguments instead of its inherent three place arguments. A similar process characterizes reciprocity on the other hand, which means two parties or participants equally acting upon each other. The difference is the effects of the actions, which are mutually received or suffered by both participants, and the fact that two affixal processes, which realize a single unit called 'circumfix 'is used.

This study, apart from the findings highlighted above, also found that both processes result in valency decrease and adjustment in semantics of the basic structure.

The findings in this study can be replicated in some related languages or compared to other languages to examine the similarities or dissimilarities of these intricate processes. It can also stimulate further studies in syntax, morphology, and morphosyntax, which will make tangible contribution to the African linguistic literature. 


\section{References}

Blench, R. and Kay Williamson, 1988. Bantoid revisited. Paper presented at the 18th Colloquium of African languages, Leiden.

Brady, J. and E.H. Gerald, 1982. General chemistry: Principle and structure. New York: John Wiley \& Sons.

Croizer, D.H. and Roger M. Blench, 1992. An index of Nigerian languages ( $2^{\text {nd }}$ edition). Dallas: SIL.

Crystal, D., 2008. A dictionary of linguistics and phonetics. Oxford: Blackwell.

Haspelmath, M. and D.A. Sims, 2012. Understanding morphology ( $2^{\text {nd }}$ Edition $)$. London: Hodder Education.

Imoh, P.M., 2013. Verbal extensions: Valency increasing operations in Basà verbal system Paper presented at the West African Languages Congress (WALC) and $26^{\text {th }}$ Annual Conference of the Linguistic Association of Nigeria (26 2 th $A N), 29^{\text {th }}$ July to $2^{\text {nd }}$ August 2013, University of Ibadan, Nigeria.

Imoh, P.M. and G. Isa, 2015. Exploring the syntactic effects of verbal extensions in Basà. In N. Ndimele (ed.) Language endangerment: Globalization and the fate of minority languages in Nigeria, a festschrift for Appolonia Uzuoka Okudishu, 441-451. Port Harcourt: M\&J Grand Orbit Communication Limited.

Imoh, P.M., 2016. Verbal extensions: Valency increasing operations in Basà verbal system. In Muazu, M. (ed.) Language, communication and society. A festschrift in honour of Professor B.R. Badejo. (ms).

Kozinceva, N., 1981. Refleksivnyeglogoly v armjanskomjazyke. In V.S. xrakovskij (ed.). Zalogovyekonstrukcii v raznostrukturnyxjazykax, 81-98. Leningrad:Nauka.

Leslau, W.C., 1995. Reflexive grammar of Amharic. Wiesbaden: Harrassowitz.

Lyons, J., 1969. Introduction to theoretical linguistics. Cambridge: Cambridge University Press.

Matthews, P.H., 2007. Oxford concise dictionary of linguistics. Oxford: Oxford University.

Mazengia, S., 2012. Valency in Amharic and Oromo reflexives and reciprocals. Retrieved from http://etd.aau.edu.et/handle/123456789/164

Mutaka, N., 2000. An introduction to African linguistics. Berlin: Lincom Europa.

Tesniere, L., 1969. Elements de syntax e structure. Paris: Libraire C. Klincksiek. 